\title{
Portada: Revolt. Instalación sonora/cinética
}

Fernando Godoy, artista sonoro, Tsonami

fergodoym@gmail.com

Rodrigo Ríos Zunino, artista sonoro soundofku@gmail.com

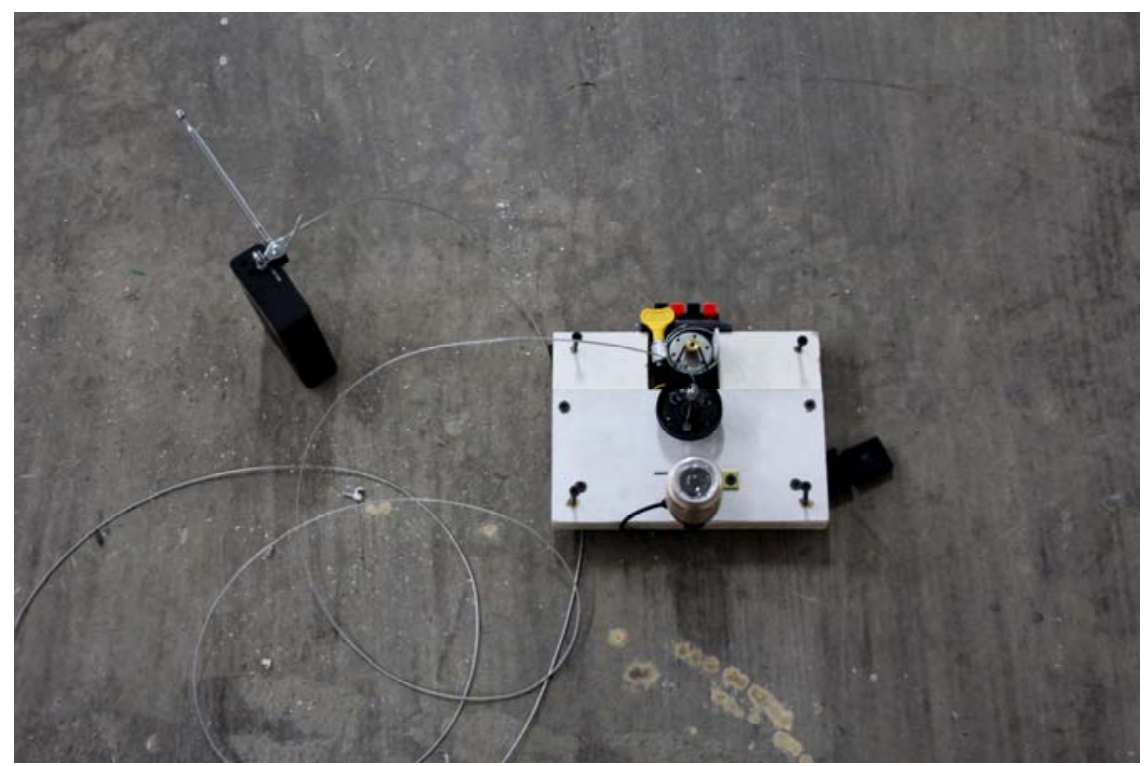

Todas las imágenes son de Rodrigo Ríos Zunino, 2016

Revolt nace por encargo para el Festival Internacional de Radioarte Radio Revolten, que se realizó en la ciudad de Halle, Alemania, en septiembre de 2016. A partir de una re-lectura de la historia del Fasat Alfa, el fallido primer satélite chileno que nunca logró entrar en órbita, la obra explora los fenómenos de transmisión y recepción de radiofrecuencias, así como las ideas de giro, rotación y circumambulación. 
Estos fenómenos pueden ser observados en las órbitas planetarias, los electrones, la rotación de la Tierra, el micro y macro mundo físico, así como también en tradiciones ancestrales presentes en todo el mundo. Los derviches sufíes, los monjes budistas que caminan alrededor de las stupas, los musulmanes girando alrededor de la Kaaba, las naciones americanas del norte con sus rituales de danza al sol alrededor del Árbol de la Vida y, así, la lista sigue y sigue. El que las personas giren sobre sí mismas o alrededor de algo -generalmente totémico/simbólico/sagrado- es tan antiguo como los seres humanos y, a la vez, el giro es un fenómeno vital en la exploración del universo. De esta manera, Revolt intenta explorar artísticamente los fenómenos vibratorios y rotatorios, como también las ondas sonoras, electromagnéticas y mecánicas propagadas dentro de un espacio específico. 
Panambí n. 4 Valparaíso jun. 2017 ISSN 0719-630X. 13-18.

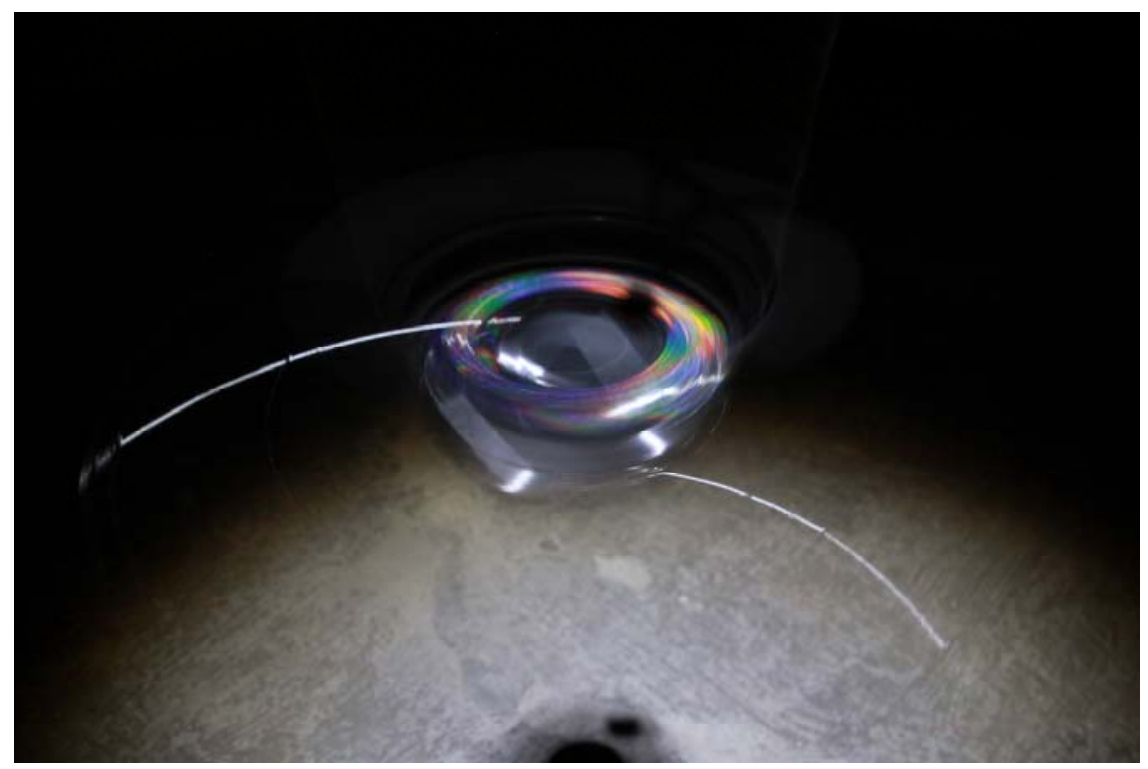

Estamos girando a través de un espacio sin fin a una velocidad inconcebible, a nuestro alrededor todo esta girando, todo está en movimiento, todo es energía.

Nikola Tesla 


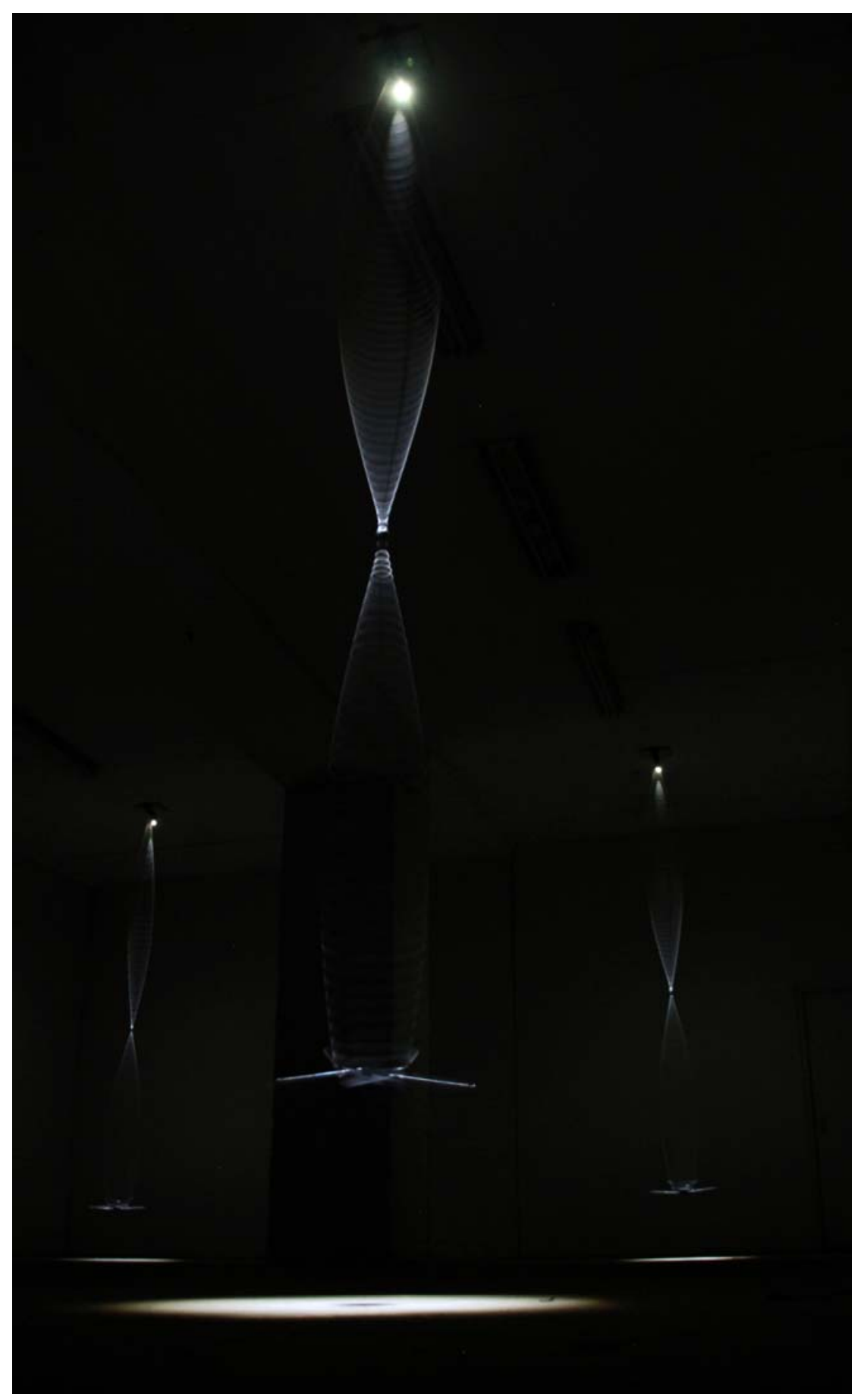


A nivel visual, la manifestación y la modulación de vibraciones pueden ser observadas en ondas sinusoidales que se forman en las cuerdas de las que cuelgan un conjunto de radios FM. En otro nivel, la obra funciona como una suerte de coreografía en la cual estas radios giratorias cambian de velocidades y direcciones, produciendo diferentes movimientos pendulares, y se metamorfosean en suertes de platillos/satélites o extraños objetos no identificados, los que, a su vez, capturan sonidos que terminan de dibujar una partitura de movimientos y luces.

Nada está inmóvil; todo se mueve; todo vibra.

Principio de Vibración, El Kybalion 


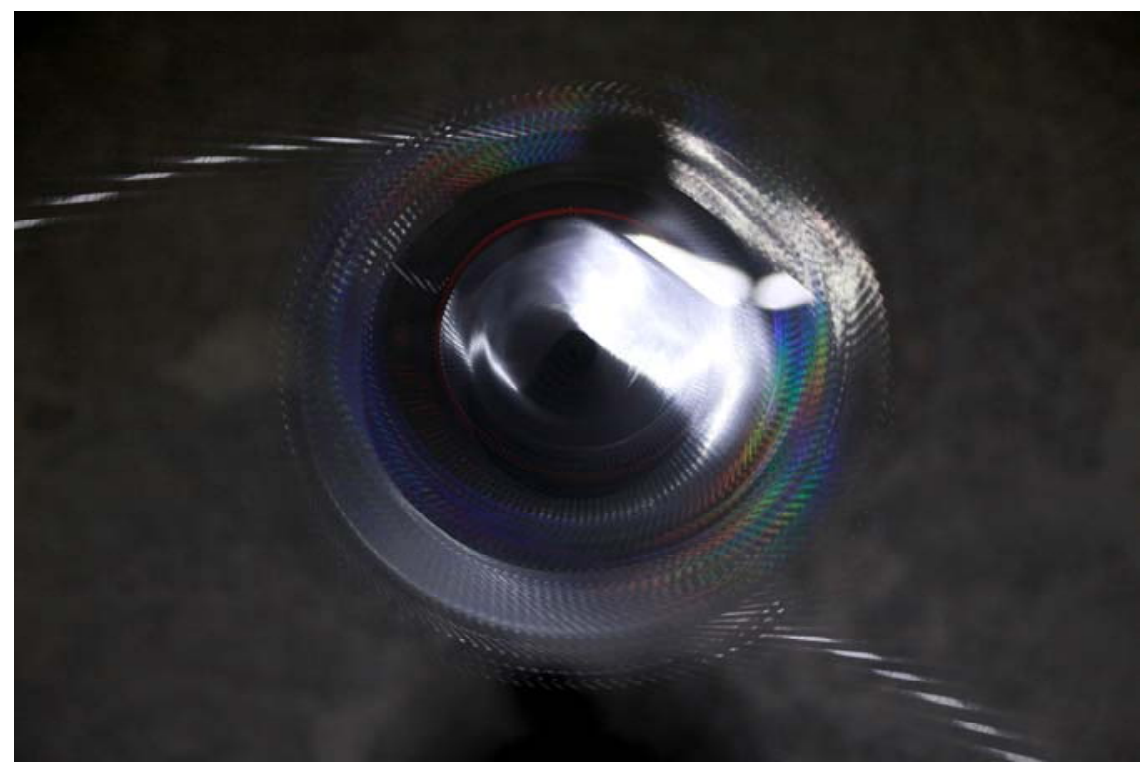

En lo sonoro, la pieza utiliza la recepción de las pequeñas radios para sintonizar una composición que es enviada vía radiofrecuencias por un transmisor ubicado en el mismo espacio de exhibición. Al mismo tiempo, el efecto de giro de las radios produce una transformación, debido a las diferentes velocidades creando un efecto tipo leslie/doppler que modula los sonidos de la composición. Estos sonidos están principalmente compuestos de armónicos de cuencos y grabaciones electromagnéticas, conformando una suerte de escultura sonoro/cinética que busca construir un puente entre distintos estados de la percepción humana.

Video a la documentación de la obra: https://youtu.be/k0Rae6Q0TRO Web Fernando Godoy: http://www.00000000.info/ Web Rodrigo Ríos Zunino: http://www.rprz.info/ 